\title{
EDITORIAL
}

\section{Deadlines are for other people}

Deadlines are an unvarying aspect of publication, whether one is a journalist working for a tabloid newspaper or concerned with the publication of a scientific journal. Reactions to deadlines are extremely variable, especially when the deadlines are imposed by other people - which often causes resentment because someone else is trying to impose their pattern of work and their priorities on to your own. Research scientists are increasingly having to learn to adapt to the strict deadlines imposed by grant-providers such as the European Commission, which lead to much late-night working and a great deal of business for express couriers to Brussels.

I must admit to a dread of deadlines. When I receive a letter from an editor reminding me that the deadline for my contribution is rapidly approaching, or even past, and that I am holding up the publication of my fellow scientists, I get an intense feeling of guilt and turn quickly to my word processor or reference files. I should know better, because I suspect that the same letter is sent to all contributors, for if I drop everything and put a great effort into completing the work, like as not the proofs do not materialize for months or, as recently, years.

I have discovered two key facts about deadlines: first, that the further off a deadline is the more difficult it is to meet it; and second, that there are a number of authors who have a cavalier attitude to deadlines, taking the view that they are set for other people.

What has this to do with the British Journal of Nutrition, you may ask? Publishing a scientific journal is, like all publications, carried out against a series of deadlines marking key dates by which material, that is a sufficient number of papers, duly edited and marked for the printer, must be ready, together with cover details, a contents list and an editorial, to go to the press. This interface between the scientific world of the journal and the press is a very important one.

The printer has some large and sophisticated equipment committed to a scheduled work programme. Alongside this equipment are the people who compose the text for publication, whose working life is dominated by time and performance; thus for the printer time is serious money, so that keeping to schedules and deadlines is essential for the economics of publication.

Our Journal deadlines earlier in the process are slightly more relaxed. The members of the Editorial Board have about five weeks for the initial review. These times have to be flexible because the members of the Editorial Board are working for love, or something; certainly the one lunch every year and a free copy of the Journal are not an overly generous reward for their contribution. Editors are also dependent on referees working to a deadline, but again other more pressing matters often have to be given priority over the paper sitting on their desk.

Once the Editorial Reports reach the Journal Office they are sent to me; my target is to return the reports with a suitable letter against a deadline of one week. The paper and report then go to the author and, by tradition, we set an effective deadline of three months against a threat to consider the revised paper as a new one if not returned within this time period. My own reaction when getting a paper back from a journal is to try to get it back as soon as possible, usually because I have new work in hand and also because the very idea that the paper has not been accepted is an annoyance to be disposed of quickly. I do realize that it may not be possible to drop everything to deal with revising the paper, especially if other authors have to be consulted. 
This raises one concern that is troubling many journals, namely the tendency for papers to have a very large number of authors. I wonder whether they have all contributed to writing the paper, which I think is a reasonable definition of an author. I find it difficult to visualize more than, say, five people being able to work effectively together in the process of writing, and many people feel that two authors is probably optimal. I like the concept of authorship used in the American Journal of Clinical Nutrition, in which one author should be responsible for the work described in one paper as a whole. I suspect that multiple authorship is symptomatic of the importance of citations rather than any fundamental change in the writing of papers.

However, I digress. To return to deadlines: our deadlines become more critical as the paper nears publication, and those for returning proofs are very critical indeed for our publication schedules. Some authors seem very relaxed, not to say somnolent, when dealing with proofs. One almost believes that they are quite happy for typographical or other errors to go into print. Whatever their reasons, the slow returning of proofs can create delays that are serious because they impose extra work for Journal staff having to chase authors and may directly affect publication schedules. These are real instances where one author can delay the publications of his or her peers. It often seems that the offending author believes that the deadlines were set for other lesser mortals.

My parting shot is that deadlines do matter, especially at the interface with the printer, and that responding promptly to deadlines reflects a proper concern for your fellow researchers.

D. A. T. Southgate 